This is an Accepted Version ("postprint") of a manuscript. The Version of Record of this manuscript has been published and is available in PSYCHOLOGY, HEALTH AND MEDICINE, 2015, http://www.tandfonline.com/10.1080/13548506.2015.1028945

The manuscript has been reformatted slightly from the form in which it was originally submitted (tables have been inserted into the main text, and an electronic supplementary materials document has been included).

\title{
Do hotter temperatures increase the incidence of self-harm hospitalisations?
}

Matt N. Williams ${ }^{1}$

Stephen R. Hill

John Spicer

Massey University, New Zealand

${ }^{1}$ Corresponding author.

School of Psychology

Massey University

Private Bag 102904

North Shore

Auckland 0745

New Zealand

mattnwilliams@gmail.com

Ph: +64 92136117

Fax: +64 94148157 


\title{
Do hotter temperatures increase the incidence of self-harm hospitalisations?
}

\begin{abstract}
A relationship between air temperature and the incidence of suicide has been established in a number of previous studies. Interestingly, the relationship between geographical variation in temperature and suicide incidence has generally been found to be negative, while the relationship between temporal variation in temperature and suicide incidence has generally been found to be positive. It is less clear, however, how temperature relates to the incidence of self-harm. This topic is of particular importance given the presence of ongoing global warming. This study investigated the relationship between temperature and the incidence of self-harm resulting in hospitalisation in New Zealand. Self-harm hospitalisations by date and district for 1993-2009 were obtained from the Ministry of Health. Meteorological data was obtained from NIWA. Generalized linear mixed models were used to estimate the effects of three different components of variation in temperature: Geographical, seasonal, and irregular. Irregular (random) daily variation in temperature had a modest positive relationship with the incidence of acts of self-harm resulting in hospitalisation, with about $0.7 \%$ extra incidents for every $1^{\circ} \mathrm{C}$ increase in temperature. However, there was no strong evidence for a positive effect of either seasonal or geographical variation in temperature. We conclude that temperature does appear to bear some relation to the incidence of self-harm, with irregular daily variation in temperature having a positive effect. However, inconsistencies in the effects of different components of variation in temperature make it challenging to accurately predict how global warming will influence the incidence of self-harm.
\end{abstract}

\section{Keywords}

Self-harm; self-injury; temperature; climate change; global warming. 


\section{Introduction}

The effect of temperature on the incidence of fatal self-harm (i.e., suicide) has been studied since at least the late 1800s (Morselli, 1882). Interestingly, studies comparing different geographical regions have tended to find that colder areas have higher suicide rates (Lester, 1999; Rotton, 1986; Souêtre, Wehr, Douillet, \& Darcourt, 1990), while studies investigating the effects of temporal variation in temperature within individual regions have tended to find positive effects (Ajdacic-Gross et al., 2007; Deisenhammer, Kemmler, \& Parson, 2003; Helama, Holopainen, \& Partonen, 2013; Kim, Kim, \& Kim, 2011; Page, Hajat, \& Kovats, 2007). What has been studied less is how temperature relates to the incidence of acts of self-harm more generally, including non-fatal self-harm. The issue of the effects of temperature on self-harm is of particular importance given the presence of ongoing anthropogenic global warming (IPCC, 2013).

The small number of studies that have attempted to investigate the relationship between temperature and the incidence of self-harm have tended to focus on the effects of temporal variation in temperature. Furthermore, the focus has tended to be on seasonal variation. For example, a study of admissions to an emergency department in Turkey (Doganay et al., 2003) found a strong correlation, $r=.81$, between the average number of suicide attempts in each month of the calendar year and temperature. An Italian study of suicide attempts for 1974-1994 also found a strong and positive (but not significant) correlation between mean temperature and the number of suicide attempts across the twelve months of the calendar year, $r=.49$ (Preti, 1997). These findings are consistent with studies of the seasonal distribution of self-harm, which tend to find peaks in the warmer months of spring (Jessen et al., 1999; Jessen, Steffensen, \& Jensen, 1998; Rock \& Hallmayer, 2008) or summer (Masterton, 1991).

A study of 12,379 parasuicide admissions in Oxford for 1976-1989 (Barker, Hawton, Fagg, \& Jennison, 1994) took the alternative approach of analysing data at the daily level. This meant that their study estimated the combined effects of both seasonal and irregular (random) variation in temperature. A significant but small correlation between parasuicide admissions and maximum temperature was found for women, $r=.04$, but not men. A study of hospital admissions in Helsinki attempted to directly estimate the effect of irregular variation in temperature on suicide attempts by calculating the difference between daily observed temperatures and seasonal norms (Hiltunen et al., 2012). The resulting estimated effect of temperature was small and not statistically significant. 
In general, the effect of irregular daily variation in temperature on the incidence of self-harm is as yet not well established. Similarly, we were unable to find any study that specifically assessed the effect of geographical variation in temperature on the incidence of self-harm. These two components of variation in temperature are of particular interest for different reasons. The effects of irregular variation in temperature are a valuable object of study because, due to its random and unpredictable nature, irregular daily variation is less likely to be subject to important confounds than other components of temperature variation. On the other hand, while the effects of geographical variation in temperature may be difficult to separate from demographic or cultural differences between populations living in different areas, investigation of the relationship between geographical variation in temperature and self-harm is still valuable: It may help to inform inferences about the effects of long-term, sustained differences in climate, such as those occurring due to anthropogenic climate change.

The current study therefore aims to specifically estimate the effects geographical, seasonal, and irregular variation in temperature on the incidence of acts of self-harm resulting in hospitalisation in New Zealand. Furthermore, this study aims to discuss what this information can (and cannot) tell us about how the incidence of self-harm is likely to be affected by anthropogenic climate change.

\section{Methods}

\section{Description of setting}

New Zealand is an island nation with approximately 4.5 million inhabitants (MacPherson, 2014). Its climate ranges from warm and subtropical in the north, to cool and temperate in the south, with severe alpine conditions in some mountainous regions (Mackintosh, 2001). The most common ethnicities are European (74\% in 2013), Māori (15\%), Asian (12\%), and Pacific peoples (7\%) (Statistics New Zealand, 2014).

\section{Hospitalisations Data}

The New Zealand Ministry of Health provided nationwide data listing public hospital discharges with a discharge date between 1 January 1993 and 31 December 2009 for which at 
least one of the causes of hospitalisation was self-harm (ICD-9 codes E950-E958). These data were collated by date of injury and the patient's territorial local authority area (hereafter “district”) of domicile. 67 districts currently exist in New Zealand. 462 hospitalisations with a district of "overseas/other” listed were included in the national descriptive statistics reported, but excluded from analyses of the effects of temperature.

The date of injury for each incident was not necessarily the date of admission to hospital. Where multiple acts of self-harm contributed to a single hospitalisation, the date of the most recent act of self-harm was utilised as the date of injury. Furthermore, where the same act of self-harm appeared to have caused multiple hospitalisations (i.e., when the patient and the most recent date of injury was the same), only the first admission was counted. In fewer than $1 \%$ of cases, the patient died in hospital. These cases were included in our analyses.

The original source of the hospitalisation data was the National Minimum Dataset for hospital events. A problem with this dataset was inconsistency in terms of whether or not short emergency department stays were recorded, with different reporting practices used by different district health boards, as well as changes in reporting practices over time. We followed the practice of the Ministry of Health (2012) in excluding emergency department stays of less than two days from analysis, resulting in the exclusion of 24,906 incidents. These incidents excluded, there were a total of 47,265 incidents of self-harm resulting in hospitalisation over the study period of 17 years.

\section{Meteorological Data}

Meteorological data was obtained from NIWA's virtual climate network rather than physical weather stations. This network covers New Zealand in an interpolated regular 5km grid (see NIWA, n.d.; Tait, Henderson, Turner, \& Zheng, 2006). The use of the virtual climate network avoided problems with missing data, or with finding appropriate physical stations to represent every district. The virtual weather station closest to the city centre of the largest town or urban area within each district was used to represent that district. A virtual climate station was not available for one district, the (offshore) Chatham Islands; the Chathams AWS station was used for this district. Mean daily temperatures were calculated by taking the mean of the daily minimum and daily maximum temperatures. 


\section{Population and Demographic Data}

Annual population data by district was obtained from Statistics New Zealand, and interpolated to produce daily estimates. The percentages of the population in each district falling into various ethnicities and age groups were obtained from Statistics New Zealand (n.d.) for the censuses of 1996, 2001, and 2006. These percentages were then averaged across these time points within each district for use as controls in geographical comparison analyses.

\section{Data Analysis}

Data analysis was completed using R version 3.0.2 (R Core Team, 2013), with the package lme4 version 1.0-5 used for fitting linear mixed models (Bates, Maechler, Bolker, \& Walker, 2013). The Poisson model was used for most analyses. The Poisson model assumes that the conditional variance of the response variable is equal to the mean. Where variance in excess of the mean (i.e., overdispersion) was present the negative binomial model was used. Overdispersion was tested for by calculating the ratio of the Pearson chi-square fit statistic to the residual degrees of freedom, $\chi^{2} / d f$ (Coxe, West, \& Aiken, 2009). There was no evidence of temporal autocorrelation in any of the analyses used (e.g., lag $1 r<0.03$ in each case), meaning that an assumption that model errors were independent seemed reasonable. Confidence intervals for mixed models were calculated using the Wald method.

\section{Ethical Approval}

Ethical approval was obtained from the authors' host institution. Further information about the study's methods can be found in the Electronic Supplementary Materials.

\section{Results}

Excluding short emergency department stays, there were a total of 47,265 self-harm incidents resulting in hospitalisation in the study period. Of these, $64 \%$ were by females. The overall rate of self-harm incidents was 70.5 per 100,000 per annum. 


\section{Effects of geographical variation in temperature}

The mean temperature by district varied from $15.8^{\circ} \mathrm{C}$ in the Far North district to $9.5^{\circ} \mathrm{C}$ in Queenstown-Lakes. A simple correlation suggested that there was no evidence of a reliable relationship between self-harm rate per 100,000 and mean temperature across districts, $r=$ $.071,95 \%$ CI [-.172, .306]. Negative binomial models were also estimated in which the number of self-harm incidents resulting in hospitalisation within each district over the entire study period was the response variable. In the first model, the only predictor variables were the mean temperature within each district over the entire study period, and the logarithm ${ }^{1}$ of mean population. In this model, the slope for geographical mean temperature was negative and very small.

The results differed somewhat when a second model was estimated with additional controls: Radiation, the percentage of European, Asian and Māori residents in each district, and the percentages aged 15-39, 40-64 and 65 plus. Radiation was included as a control because the quantity of sunlight is a plausible third variable that might be related to both selfharm and temperature (see Doganay et al., 2003). In the controlled model, the point estimate of the effect of temperature was strongly positive, but the $95 \%$ confidence interval spanned zero. The coefficients for both models are displayed in Table 1.

\footnotetext{
${ }^{1}$ Given the use of a logarithmic link function as part of the negative binomial model, the log transformation allowed population size to have an additive effect. Specifically, one would expect the logarithm of population size to have a coefficient near 1, if self-harm incidence was directly proportional to population.
} 
Table 1

Coefficients for Geographical Variation Models

\begin{tabular}{lcrrrrr}
\hline & \multicolumn{3}{c}{ Uncontrolled model } & \multicolumn{3}{c}{ Controlled model } \\
& \multicolumn{3}{c}{ 95\% CI } & \multicolumn{3}{c}{$95 \%$ CI } \\
Coefficient & Est. & lower & upper & Est. & lower & upper \\
\hline Intercept & 6.654 & 6.557 & 6.754 & 6.581 & 6.472 & 6.694 \\
Log population $^{*}$ & 1.109 & 1.026 & 1.193 & 1.037 & 0.921 & 1.155 \\
Temperature $\left({ }^{\circ} \mathrm{C}\right)$ & -0.004 & -0.062 & 0.054 & 0.050 & -0.035 & 0.135 \\
Radiation $\left(\mathrm{MJ} / \mathrm{m}^{2}\right)$ & & & & 0.007 & -0.098 & 0.112 \\
Percentage European & & & & -0.026 & -0.060 & 0.005 \\
Percentage Māori & & & & -0.020 & -0.045 & 0.004 \\
Percentage Asian & & & & -0.081 & -0.166 & 0.004 \\
Percentage aged 15-39 & & & & 0.067 & -0.002 & 0.137 \\
Percentage aged 40-64 & & & & -0.001 & -0.076 & 0.074 \\
Percentage aged 65+ & & & & 0.103 & 0.044 & 0.163 \\
\hline
\end{tabular}

Notes. ${ }^{*}$ Each variable was centered around its mean across districts, except for population which was centered around the logarithm of the mean population estimate. Generalized linear model with negative binomial distribution and log link used. $N=67$ districts.

\section{Effect of seasonal variation in temperature}

There was relatively little seasonal variation in self-harm incidence, as is visible in Figure 1. The peak month was February (summer), with just 11.4\% more self-harm incidents than the nadir in July (winter). For use in multivariable analyses, the seasonal norm temperature was operationalised as the mean temperature for each day of the 365 days of the calendar year, as averaged over the entire study period within each district. The total number of acts of self-harm resulting in hospitalisation occurring on the 17 occurrences of each day of the year for each district was then used the response variable. February 29 was excluded, given that this day occurred just 4 times over the study period. A generalized linear mixed model with a Poisson distribution and log link was then fit, with population size was controlled, and the intercept free to vary across districts. The resulting estimated effect of seasonal variation in temperature was modest (see Table 2), suggesting around $0.5 \%$ extra self-harm incidents resulting in hospitalisation per ${ }^{\circ} \mathrm{C}$. Table 2 also includes estimates from a model with solar radiation controlled, resulting in the estimated effect of temperature 
becoming approximately zero. Seasonal variation in temperature and radiation were strongly correlated in our data (mean $r=0.8$ across districts).

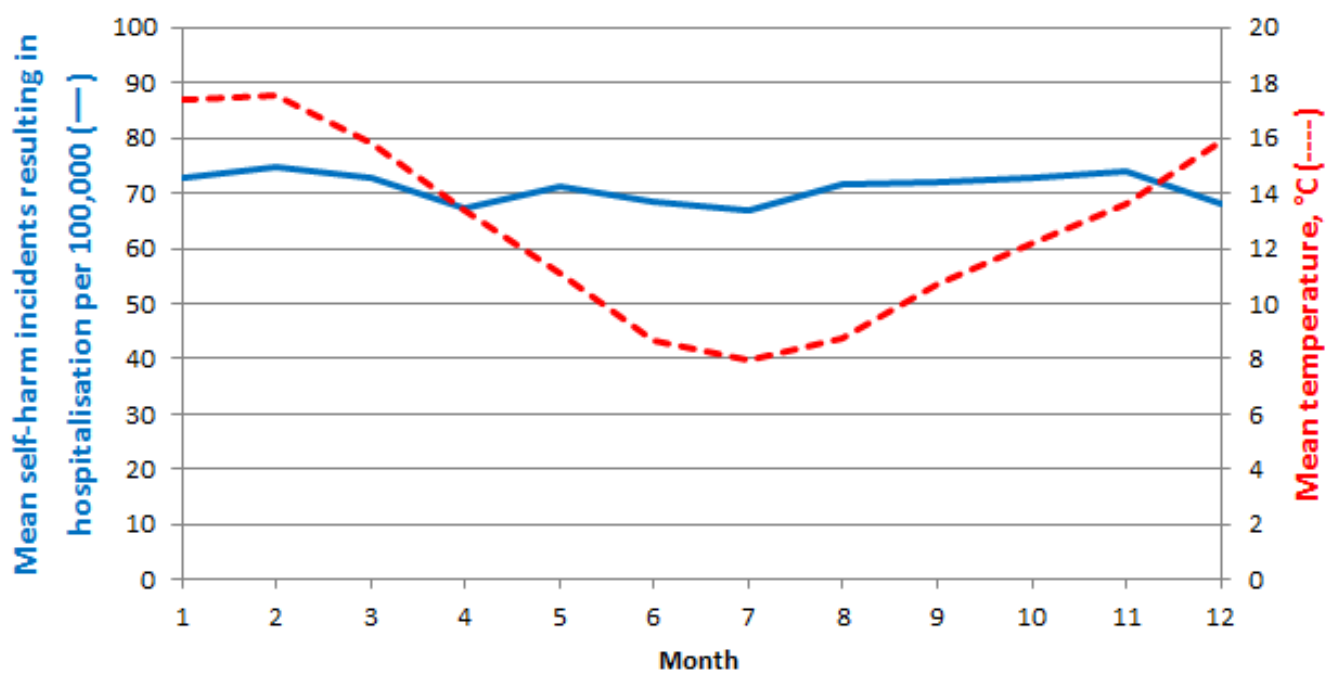

Figure 1. Self-harm incidents and temperature by month. The effect of number of days is controlled. Emergency department stays of 1 day or less are excluded.

Table 2

Coefficients for Seasonal Variation Models

\begin{tabular}{|c|c|c|c|c|c|c|}
\hline \multirow[b]{2}{*}{ Coefficient } & \multicolumn{3}{|c|}{$\begin{array}{c}\text { Model without radiation } \\
\text { controlled } \\
95 \% \text { CI }\end{array}$} & \multicolumn{3}{|c|}{$\begin{array}{c}\text { Model with radiation } \\
\text { controlled } \\
95 \% \text { CI }\end{array}$} \\
\hline & Est. & Lower & Upper & Est. & Lower & Upper \\
\hline \multicolumn{7}{|l|}{ Fixed effects } \\
\hline Intercept & 0.699 & 0.602 & 0.796 & 0.699 & 0.603 & 0.796 \\
\hline Seasonal norm temperature $\left({ }^{\circ} \mathrm{C}\right)$ & 0.005 & 0.002 & 0.008 & 0.001 & -0.004 & 0.005 \\
\hline Log population ${ }^{*}$ (log transformed) & 1.106 & 1.028 & 1.184 & 1.106 & 1.028 & 1.184 \\
\hline Radiation $\left(\mathrm{MJ} / \mathrm{m}^{2}\right)$ & & & & 0.003 & $1.9 \times 10^{-4}$ & 0.005 \\
\hline \multicolumn{7}{|l|}{ Random effects (SDs) } \\
\hline Intercept | District & 0.326 & - & - & 0.325 & - & - \\
\hline
\end{tabular}




\section{Effects of irregular daily variation in temperature}

Irregular variation in temperature was captured by calculating temperature anomalies. These anomalies were the difference between the temperature observed on a given date in a particular district, and the seasonal norm temperature for that district and day of year (as defined previously). These anomalies were then entered into a mixed model, with the number of self-harm incidents resulting in hospitalisation occurring on each date and district as the response variable, and population controlled.

In the mixed model, a random intercept across both districts and years within districts was specified. This provided a flexible control for both regional differences in self-harm rate as well as for any potential time-varying confounds producing long-term trends in self-harm incidence. The coefficients for this model are shown in Table 3. Irregular daily variation in temperature appeared to have a moderate positive relationship with self-harm incidence, with the model implying an extra $0.7 \%$ acts of self-harm resulting in hospitalisation for every $1^{\circ} \mathrm{C}$ increase in temperature. Controlling for radiation in an alternative model resulted in no observable change to the coefficient for temperature (at 3 decimal places). 
Table 3

Coefficients for Irregular Daily Variation Models

Model without radiation

Model with radiation

controlled

controlled

95\% CI

$95 \%$ CI

Est. Lower Upper Est. Lower Upper

\section{Fixed effects}

Intercept

$-2.197$

0.007

1.059

Log Population*

Radiation $\left(\mathrm{MJ} / \mathrm{m}^{2}\right)$

Temperature anomaly $\left({ }^{\circ} \mathrm{C}\right)$

$$
-2.294
$$

0.003

$-2.101$

$-2.198$

$-2.294$

$-2.101$

0.982

0.011

0.007

0.003

1.135

1.058

0.981

1.135

0.002

$4.9 \times 10-4$

0.003

\section{Random effects (SDs)}

$\begin{array}{lllll}\text { Intercept | District } & 0.319 & - & - & 0.318 \\ \text { Intercept | District/Year } & 0.265 & - & - & 0.265\end{array}$

Notes. Each variable centered around its mean, except for log population which was centered around the logarithm of the mean population. Model: Poisson generalized linear mixed model with log link. Intercepts permitted to vary within districts, and within years within each district. $N=6209$ calendar days x 67 districts less 69 days with missing temperature data $=415,934$ for model without radiation controlled. $N$ for model with radiation controlled $=415,857$ due to an additional 77 cases with missing radiation measurements. The response variable is the number of self-harm incidents occurring on a given date in a specific region.

\section{Trends in Temperature and Self-Harm}

Figure 2 shows changes over time in the mean temperature and self-harm rate in New Zealand. Over the course of the study period, mean temperatures increased in New Zealand, with an average increase of $0.01^{\circ} \mathrm{C}$ per year. On the other hand, self-harm incidents resulting in hospitalisation declined markedly, with a linear model suggesting a downward trend of 1.8 fewer incidents of self-harm resulting in hospitalisation per 100,000 per year. 


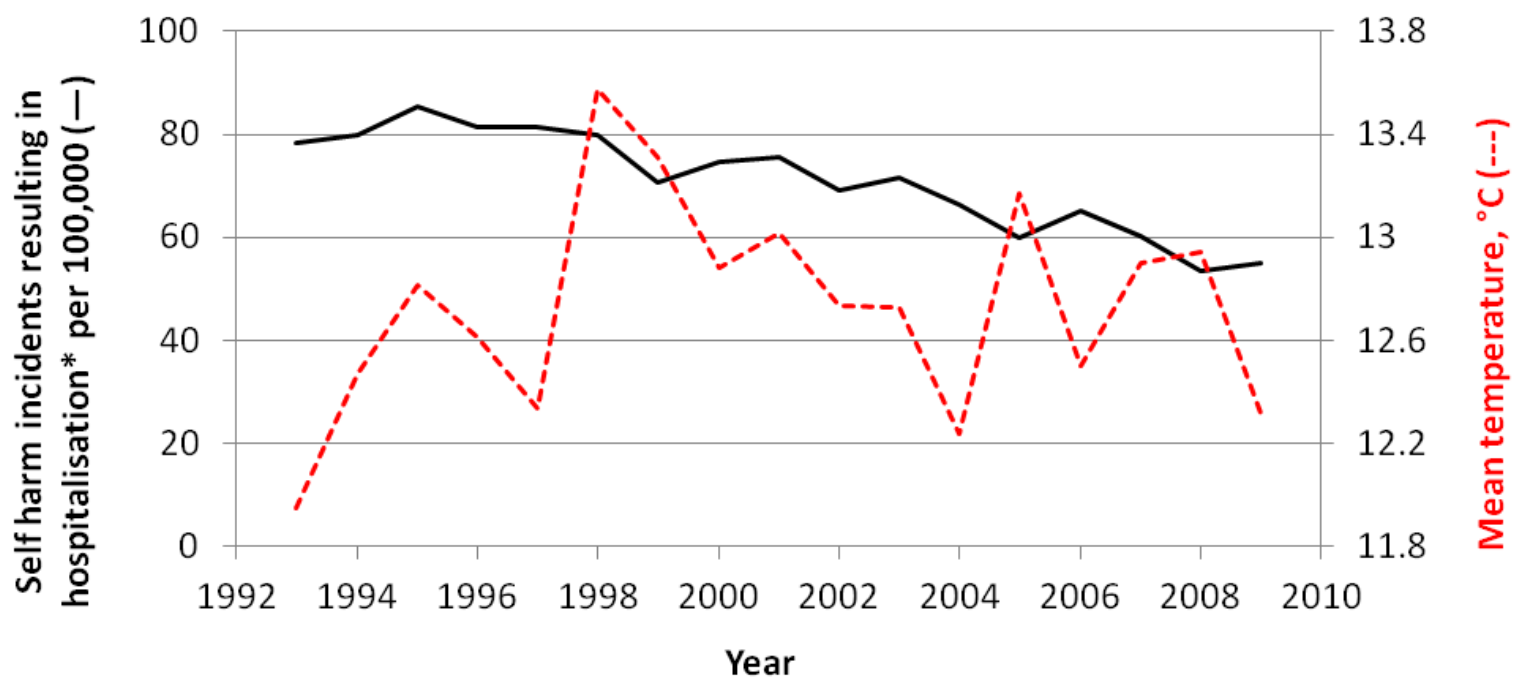

Figure 2. Trends in temperature and self-harm resulting in hospitalisation in New Zealand, 1993-2009. *Emergency department stays of one day or less are excluded.

\section{Discussion}

Our findings indicate that irregular daily variation in temperature had a small but positive relationship with the incidence of self-harm. In other words, days with hotter temperatures than the norm for that area and time of year tended to be associated with higher rates of self-harm. The size of this effect was about $0.7 \%$ extra incidents of self-harm resulting in hospitalisation per ${ }^{\circ} \mathrm{C}$. This finding is similar to that of a recent study of suicides in New Zealand, which also found a small positive effect of irregular variation in temperature (Williams, Hill, \& Spicer, in press). Of the components examined, the effects of irregular daily temperature variations are the least likely to be confounded. This finding thus might suggest that higher daily temperatures occurring as part of climate change will exert a small increasing effect on self-harm incidence (around 0.4 extra acts of self-harm per 100,000 p.a. resulting in hospitalisation per ${ }^{\circ} \mathrm{C}$, given the self-harm rate in 2009).

However, this conclusion is weakened somewhat by the lack of strong evidence for a positive effect of either seasonal or geographical variation in temperature. Seasonal variation in temperature did appear to have a positive relationship with self-harm incidence, but the relationship was small. This finding is consistent with a previous study that found limited (univariate) seasonality in suicide deaths in New Zealand (Yip, Chao, \& Ho, 1998) . Furthermore, the estimated effect of temperature was not robust to a control for radiation. Changes in solar radiation are the major factor driving seasonality in temperatures, but 
seasonal variation in radiation and temperature are not perfectly correlated. This meant that the independent effects of the two variables could be estimated. The fact that radiation had a positive coefficient when both variables were included as predictors suggests that seasonal variation in radiation may exerts some influence on self-harm incidence via a pathway other than by affecting temperature.

We were unable to confidently establish the direction or size of the relationship between geographical variation in temperature and the incidence of acts of self-harm resulting in hospitalisation. In a negative binomial model the estimated effect of geographical variation in temperature (i.e., mean temperature by district over the entire study period) had a very wide confidence interval, ranging from a strong negative effect to a strong positive one. This analysis was limited both by the small effective sample size in terms of geographical areas (just 67 districts), and the possibility of confounding by uncontrolled economic or demographic variables. This said, geographical comparison analyses do allow for at least some insight into the effects of long term differences in climate, as opposed to short-term variation in weather, and as such further research on this topic over larger geographical regions may be useful.

It was interesting to note that self-harm incidents resulting in hospitalisation (excluding short emergency department stays) declined over the study period, despite an increase in temperatures. It seems likely, however, that the downward trend in self-harm hospitalisations may be at least partially due to changes in medical practice and administration, such as increased use of community-based rather than inpatient mental health care (Ministry of Health, 2012).

This study did not attempt to uncover the causal mechanism of the relationship between temperature and self-harm. Little theoretical work has been attempted in this area, although the related topic of suicide seasonality has drawn far greater theoretical attention (for a review see Ajdacic-Gross, Bopp, Ring, Gutzwiller, \& Rossler, 2010). It is also worth acknowledging that our study focused only on the most serious cases of self-harm: those resulting in hospitalisation.

Overall, it remains challenging to predict how climate change will affect the incidence of self-harm in New Zealand. While the estimated effect of irregular daily variation in temperature appears to suggest that global (and regional) warming may increase self-harm incidence slightly, this conclusion would be more strongly justified were we able to show that seasonal and geographical variation had similar effects. A lack of consistency in the apparent effects of different components of variation in temperature raises the concern that humans 
may react differently to long-term, sustained differences in temperature than they do to shortterm variation in temperature. This lack of consistency makes it more difficult to infer the future impact of a sustained increase in temperatures. None of the analyses in isolation are ideal as a basis for drawing inferences about climate change: The effects of irregular daily variation in temperature may not adequately approximate the effects of more sustained temperature changes, while analyses of the effects of seasonal and geographical variation are vulnerable to confounding. There is also the possibility that climate change may affect mental health via causal pathways not examined in this study (see Berry, Bowen, \& Kjellstrom, 2010).

In conclusion, this study demonstrates that irregular daily variation in temperature is positively related to the incidence of self-harm resulting in hospitalisation in New Zealand. However, predicting how climate change will affect self-harm remains challenging. Future research focused on issues such as the relationship between geographical variation in temperature and self-harm, and the mechanism of the relationship between temperature and self-harm, may facilitate firmer conclusions about how climate change will affect self-harm rates. 


\section{References}

Ajdacic-Gross, V., Bopp, M., Ring, M., Gutzwiller, F., \& Rossler, W. (2010). Seasonality in suicide - A review and search of new concepts for explaining the heterogeneous phenomena. Social Science \& Medicine, 71(4), 657-666.

http://doi.org/10.1016/j.socscimed.2010.05.030

Ajdacic-Gross, V., Lauber, C., Sansossio, R., Bopp, M., Eich, D., Gostynski, M., ... Rössler, W. (2007). Seasonal associations between weather conditions and suicide-evidence against a classic hypothesis. American Journal of Epidemiology, 165(5), 561-569. http://doi.org/10.1093/aje/kwk034

Barker, A., Hawton, K., Fagg, J., \& Jennison, C. (1994). Seasonal and weather factors in parasuicide. The British Journal of Psychiatry, 165(3), 375-380. http://doi.org/10.1192/bjp.165.3.375

Bates, D., Maechler, M., Bolker, B., \& Walker, S. (2013). lme4: Linear mixed-effects models using Eigen and S4 (Version 1.0-5). Retrieved from http://cran.rproject.org/web/packages/lme4/index.html

Berry, H. L., Bowen, K., \& Kjellstrom, T. (2010). Climate change and mental health: A causal pathways framework. International Journal of Public Health, 55(2), 123-132. http://doi.org/10.1007/s00038-009-0112-0

Coxe, S., West, S. G., \& Aiken, L. S. (2009). The analysis of count data: A gentle introduction to poisson regression and its alternatives. Journal of Personality Assessment, 91(2), 121-136. http://doi.org/10.1080/00223890802634175

Deisenhammer, E. A., Kemmler, G., \& Parson, P. (2003). Association of meteorological factors with suicide. Acta Psychiatrica Scandinavica, 108(6), 455-459. http://doi.org/10.1046/j.0001-690X.2003.00219.x 
Doganay, Z., Sunter, A. T., Guz, H., Ozkan, A., Altintop, L., Kati, C., ... Guven, H. (2003). Climatic and diurnal variation in suicide attempts in the ED. The American Journal of Emergency Medicine, 21(4), 271-275. http://doi.org/10.1016/S0735-6757(03)00039-1

Helama, S., Holopainen, J., \& Partonen, T. (2013). Temperature-associated suicide mortality: contrasting roles of climatic warming and the suicide prevention program in Finland. Environmental Health and Preventive Medicine, 18(5), 349-355. http://doi.org/10.1007/s12199-013-0329-7

Hiltunen, L., Ruuhela, R., Ostamo, A., Lönnqvist, J., Suominen, K., \& Partonen, T. (2012). Atmospheric pressure and suicide attempts in Helsinki, Finland. International Journal of Biometeorology, 56(6), 1045-1053. http://doi.org/10.1007/s00484-011-0518-2

IPCC. (2013). Climate change 2013: The physical science basis. Contribution of Working Group I to the fifth assessment report of the Intergovernmental Panel on Climate Change. Cambridge, United Kingdom and New York, NY, USA: Cambridge University Press. Retrieved from https://www.ipcc.ch/report/ar5/wg1/

Jessen, G., Andersen, K., Arensman, E., Bille-Brahe, U., Crepet, P., De Leo, D., ... Wasserman, D. (1999). Temporal fluctuations and seasonality in attempted suicide in Europe: Findings from the WHO/EURO multicentre study on parasuicide. Archives of Suicide Research, 5(1), 57-69. http://doi.org/10.1080/13811119908258315

Jessen, G., Steffensen, P., \& Jensen, B. F. (1998). Seasons and meteorological factors in suicidal behaviour: Findings and methodological considerations from a Danish study. Archives of Suicide Research, 4(3), 263-280. http://doi.org/10.1080/13811119808258301

Kim, Y., Kim, H., \& Kim, D.-S. (2011). Association between daily environmental temperature and suicide mortality in Korea (2001-2005). Psychiatry Research, 186(2-3), 390-396. http://doi.org/10.1016/j.psychres.2010.08.006 
Lester, D. (1999). Climatic data and national suicide and homicide rates. Perceptual and Motor Skills, 89(3), 1036. http://doi.org/10.2466/pms.1999.89.3.1036

Mackintosh, L. (2001). Overview of New Zealand climate. Retrieved 10 January 2012, from http://www.niwa.co.nz/education-and-training/schools/resources/climate/overview MacPherson, L. (2014). National population estimates: At 30 June 2014. Retrieved 29 January 2015, from http://www.stats.govt.nz/browse_for_stats/population/estimates_and_projections/Nati onalPopulationEstimates_HOTPAt30Jun14.aspx

Masterton, G. (1991). Monthly and seasonal variation in parasuicide. A sex difference. The British Journal of Psychiatry, 158(2), 155-157. http://doi.org/10.1192/bjp.158.2.155

Ministry of Health. (2012). Suicide facts: Deaths and intentional self-harm hospitalisations 2010. Wellington, New Zealand. Retrieved from http://www.health.govt.nz/publication/suicide-facts-deaths-and-intentional-self-harmhospitalisations-2010

Morselli, E. A. (1882). Suicide: An essay on comparative moral statistics. New York: Appleton.

NIWA. (n.d.). CliFlo national climate database. Retrieved 3 October 2013, from http://cliflo.niwa.co.nz/

Page, L. A., Hajat, S., \& Kovats, R. (2007). Relationship between daily suicide counts and temperature in England and Wales. The British Journal of Psychiatry, 191(2), 106112. http://doi.org/10.1192/bjp.bp.106.031948

Preti, A. (1997). The influence of seasonal change on suicidal behaviour in Italy. Journal of Affective Disorders, 44(2-3), 123-130. http://doi.org/10.1016/S0165-0327(97)000359 
R Core Team. (2013). R: A language and environment for statistical computing (Version 3.0.2). Vienna, Austria. Retrieved from http://www.R-project.org/

Rock, D. J., \& Hallmayer, J. F. (2008). The seasonal risk for deliberate self-harm. Crisis: The Journal of Crisis Intervention and Suicide Prevention, 29(4), 191-201. http://doi.org/10.1027/0227-5910.29.4.191

Rotton, J. (1986). Determinism redux: climate and cultural correlates of violence. Environment and Behavior, 18(3), 346-368. http://doi.org/10.1177/0013916586183003

Souêtre, E., Wehr, T. A., Douillet, P., \& Darcourt, G. (1990). Influence of environmental factors on suicidal behavior. Psychiatry Research, 32(3), 253-263. http://doi.org/10.1016/0165-1781(90)90030-9

Statistics New Zealand. (2014). 2013 Census QuickStats about culture and identity. Retrieved 29 January 2015, from http://www.stats.govt.nz/Census/2013-census/profile-andsummary-reports/quickstats-culture-identity/ethnic-groups-NZ.aspx

Statistics New Zealand. (n.d.). Estimated resident population (ERP), subnational population by ethnic group, age, and sex, at 30 June 1996, 2001, 2006, and 2013. Retrieved 14 January 2015, from http://nzdotstat.stats.govt.nz/wbos/Index.aspx?DataSetCode=TABLECODE7512

Tait, A., Henderson, R., Turner, R., \& Zheng, X. (2006). Thin plate smoothing spline interpolation of daily rainfall for New Zealand using a climatological rainfall surface. International Journal of Climatology, 26(14), 2097-2115. http://doi.org/10.1002/joc.1350

Williams, M. N., Hill, S. R., \& Spicer, J. (in press). Will climate change increase or decrease suicide rates? The effect of temperature on suicide incidence in New Zealand. Climatic Change. 
Yip, P. S. F., Chao, A., \& Ho, T. P. (1998). A re-examination of seasonal variation in suicides in Australia and New Zealand. Journal of Affective Disorders, 47(1-3), 141150. http://doi.org/10.1016/S0165-0327(97)00135-3 


\section{Electronic Supplementary Materials}

The following supplementary materials provide extra information about the method and results of the study that is not included in the main text of the article due to space restrictions.

\section{Additional Information about Methods}

\section{Meteorological data}

As mentioned in the article text, a virtual climate station was selected for each district by choosing the virtual station closest to the town centre of the most populous urban area or town within that district. Specifically, this was accomplished by obtaining the estimated resident population by urban area in New Zealand for 1996 to 2007 from Statistics New Zealand's InfoShare website (Statistics New Zealand, 2012), and linking each district with the most populous urban area within it. In the cases of four districts (Chatham Islands, Hurunui, Kapiti Coast, and Tasman), manual selection of the largest town was necessary due either to no centre defined as an "urban area” being listed in the Infoshare data, or the largest urban area not corresponding with the largest distinct town in the district (e.g., due to an "urban area" encompassing two towns in different districts). Secondly, the centre of the largest town or urban area was defined as per Google Maps, and its geographical co-ordinates obtained from the iTouchMaps tool. Finally, the virtual climate station within the district nearest the town centre was identified using the NIWA CliFlo database (NIWA, n.d.). In a very small number of cases, the virtual climate station nearest the town centre fell outside the boundaries of the district itself; in these cases the station nearest to the town centre but within the district was used. The climate stations used to represent the climate of each district are listed in ESM Table 1.

As mentioned in the text, there was one district for which virtual climate station data was not available: The Chatham Islands. This was due to the Chathams, which are approximately $680 \mathrm{~km}$ southeast of the North Island, falling outside the range of the virtual climate network. A physical station were therefore utilised for the territory: the Chatham AWS station. There was a small quantity of missing data for this station: 69 days with missing temperature measurements, and 116 with missing radiation measurements. Missing data was dealt with by listwise deletion given its small quantity. 
ESM Table 1

Virtual Climate Stations Used

\begin{tabular}{|c|c|c|c|c|c|}
\hline District & Biggest urban area & $\begin{array}{r}\mathrm{VCN}^{1} \\
\text { agent } \\
\text { no. }\end{array}$ & Latitude & Longitude & $\begin{array}{r}\text { Km } \\
\text { from } \\
\text { town } \\
\text { centre }\end{array}$ \\
\hline Ashburton District & Ashburton Urban Area & 19146 & -43.925 & 171.725 & 2.6 \\
\hline Auckland & Auckland Urban Area & 25396 & -36.875 & 174.775 & 3.1 \\
\hline Buller District & Westport Urban Area & 18772 & -41.775 & 171.625 & 2.8 \\
\hline Carterton District & Carterton Urban Area & 30879 & -41.025 & 175.525 & 0.5 \\
\hline Central Hawke's Bay District & Waipukurau Urban Area & 31069 & -39.975 & 176.575 & 2.8 \\
\hline Central Otago District & Alexandra Urban Area & 12937 & -45.225 & 169.375 & 2.7 \\
\hline Chatham Islands Territory & Waitangi & $6191^{2}$ & -43.95 & -176.567 & 0.5 \\
\hline Christchurch City & Christchurch Urban Area & 20810 & -43.525 & 172.625 & 1.2 \\
\hline Clutha District & Balclutha Urban Area & 13350 & -46.225 & 169.725 & 1.8 \\
\hline Dunedin City & Dunedin Urban Area & 19446 & -45.875 & 170.475 & 2.2 \\
\hline Far North District & Kaitaia Urban Area & 20661 & -35.125 & 173.275 & 1.1 \\
\hline Gisborne District & Gisborne Urban Area & 30645 & -38.675 & 177.975 & 4.0 \\
\hline Gore District & Gore Urban Area & 13152 & -46.075 & 168.925 & 3.1 \\
\hline Grey District & Greymouth Urban Area & 19694 & -42.475 & 171.225 & 3.0 \\
\hline Hamilton City & Hamilton Urban Area & 30829 & -37.775 & 175.275 & 1.4 \\
\hline Hastings District & Hastings Urban Zone & 29002 & -39.625 & 176.825 & 2.0 \\
\hline Hauraki District & Waihi Urban Area & 29897 & -37.375 & 175.825 & 2.3 \\
\hline Horowhenua District & Levin Urban Area & 30825 & -40.625 & 175.275 & 1.0 \\
\hline Hurunui District & Amberley & 21366 & -43.175 & 172.725 & 2.1 \\
\hline Hutt City & Lower Hutt Urban Zone & 30748 & -41.225 & 174.925 & 2.3 \\
\hline Invercargill City & Invercargill Urban Area & 7643 & -46.425 & 168.375 & 2.1 \\
\hline Kaikoura District & Kaikoura Urban Area & 28055 & -42.375 & 173.675 & 2.9 \\
\hline Kaipara District & Dargaville Urban Area & 28571 & -35.925 & 173.875 & 1.8 \\
\hline Kapiti Coast District & Paraparaumu & 30219 & -40.925 & 175.025 & 1.8 \\
\hline Kawerau District & Kawerau Urban Area & 30029 & -38.075 & 176.725 & 2.5 \\
\hline Mackenzie District & Twizel Community Urban Area & 13690 & -44.275 & 170.125 & 2.4 \\
\hline Manawatu District & Feilding Urban Area & 30341 & -40.225 & 175.575 & 0.6 \\
\hline Marlborough District & Blenheim Urban Area & 27021 & -41.525 & 173.975 & 1.7 \\
\hline Masterton District & Masterton Urban Area & 28285 & -40.975 & 175.675 & 3.0 \\
\hline Matamata-Piako District & Morrinsville Urban Area & 30887 & -37.675 & 175.525 & 2.0 \\
\hline Napier City & Napier Urban Zone & 27434 & -39.475 & 176.875 & 3.7 \\
\hline Nelson City & Nelson Urban Area & 20719 & -41.275 & 173.275 & 0.9 \\
\hline New Plymouth District & New Plymouth Urban Area & 21442 & -39.075 & 174.075 & 2.2 \\
\hline Opotiki District & Opotiki Urban Area & 30066 & -38.025 & 177.275 & 2.2 \\
\hline Otorohanga District & Otorohanga Urban Area & 29745 & -38.175 & 175.225 & 2.0 \\
\hline Palmerston North City & Palmerston North Urban Area & 28276 & -40.375 & 175.625 & 2.9 \\
\hline Porirua City & Porirua Urban Zone & 27590 & -41.125 & 174.825 & 1.6 \\
\hline Queenstown-Lakes District & Queenstown Urban Area & 14372 & -45.025 & 168.675 & 1.2 \\
\hline Rangitikei District & Marton Urban Area & 27156 & -40.075 & 175.375 & 0.7 \\
\hline Rotorua District & Rotorua Urban Area & 27868 & -38.125 & 176.225 & 2.5 \\
\hline
\end{tabular}




\begin{tabular}{|c|c|c|c|c|c|}
\hline Ruapehu District & Taumarunui Urban Area & 28702 & -38.875 & 175.275 & 1.5 \\
\hline Selwyn District & Rolleston Urban Area & 20052 & -43.575 & 172.375 & 1.8 \\
\hline South Taranaki District & Hawera Urban Area & 21610 & -39.575 & 174.275 & 1.5 \\
\hline South Waikato District & Tokoroa Urban Area & 30961 & -38.225 & 175.875 & 0.9 \\
\hline South Wairarapa District & Featherston Urban Area & 28201 & -41.125 & 175.325 & 0.9 \\
\hline Southland District & Winton Urban Area & 10729 & -46.125 & 168.325 & 2.1 \\
\hline Stratford District & Stratford Urban Area & 21605 & -39.325 & 174.275 & 1.5 \\
\hline Tararua District & Dannevirke Urban Area & 27324 & -40.225 & 176.125 & 3.0 \\
\hline Tasman District & Richmond & 20430 & -41.375 & 173.175 & 4.1 \\
\hline Taupo District & Taupo Urban Area & 30999 & -38.675 & 176.075 & 1.3 \\
\hline Tauranga City & Tauranga Urban Area & 29942 & -37.675 & 176.125 & 3.8 \\
\hline Thames-Coromandel District & Thames Urban Area & 28786 & -37.125 & 175.575 & 3.3 \\
\hline Timaru District & Timaru Urban Area & 19840 & -44.375 & 171.225 & 3.4 \\
\hline Upper Hutt City & Upper Hutt Urban Zone & 30228 & -41.125 & 175.075 & 0.4 \\
\hline Waikato District & Huntly Urban Area & 30253 & -37.575 & 175.175 & 2.4 \\
\hline Waimakariri District & Rangiora Urban Area & 19946 & -43.325 & 172.575 & 2.9 \\
\hline Waimate District & Waimate Urban Area & 19832 & -44.725 & 171.025 & 2.0 \\
\hline Waipa District & Cambridge Urban Zone & 28244 & -37.875 & 175.475 & 1.9 \\
\hline Wairoa District & Wairoa Urban Area & 31126 & -39.025 & 177.425 & 1.3 \\
\hline Waitaki District & Oamaru Urban Area & 19617 & -45.075 & 170.975 & 2.5 \\
\hline Waitomo District & Te Kuiti Urban Area & 27114 & -38.325 & 175.175 & 1.3 \\
\hline Wanganui District & Wanganui Urban Area & 28141 & -39.925 & 175.025 & 2.0 \\
\hline Wellington City & Wellington Urban Area & 28602 & -41.275 & 174.775 & 1.3 \\
\hline Western Bay of Plenty District & Te Puke Community Urban Area & 29452 & -37.775 & 176.325 & 1.2 \\
\hline Westland District & Hokitika Urban Area & 19484 & -42.725 & 170.975 & 1.1 \\
\hline Whakatane District & Whakatane Urban Area & 27972 & -37.975 & 176.975 & 2.8 \\
\hline Whangarei District & Whangarei Urban Area & 21619 & -35.725 & 174.325 & 0.1 \\
\hline
\end{tabular}

Notes. ${ }^{1}$ VCN $=$ Virtual Climate Network. ${ }^{2}$ Physical weather station utilised (Chatham Islands AWS).

\section{Geographical units/districts}

The territorial authority areas (“districts) recorded in the hospitalisations database corresponded to the territorial authority areas existing in New Zealand prior to the creation of the Auckland "supercity" in 2010. In order to use a district classification corresponding to the current districts of New Zealand, the seven previous districts corresponding to the current Auckland supercity were amalgamated into one Auckland district in the analyses performed. These districts were Auckland city, Manukau city, Waitakere City, North Shore City, Rodney, Franklin, and Papakura.

One point of complication was that the Franklin district was actually split between the Auckland, Waikato and Hauraki districts during the creation of the Auckland supercity. 
However, since the actual street addresses of patients in the hospitalisation database were not available, it was impossible to determine whether patients listed with domiciles in the Franklin district in fact resided in an area of the district later to become part of Auckland, part of Waikato, or part of Hauraki. All patients listed as living in Franklin were therefore classified as living in the (amalgamated) Auckland district.

One other district amalgamation occurring toward the end of the study period was that of Banks Peninsula with Christchurch City in 2006. These two districts were also amalgamated for the purposes of the current study.

Our usage of the term "district" is technically at odds with the way this term is used in local government in New Zealand. We use the term to refer to all territorial authority areas, while in local government parlance there is a distinction between "district councils" and "city councils", both being types of territorial local authority. We use "district" as a generic term to refer to all types of territorial authority areas for the sake of brevity.

\section{Population estimates}

The fact that subnational population estimates were required for a longer period than that readily available in any single data source using consistent boundaries necessitated several adjustments. The following steps were used to obtain daily population estimates by district for the full study period (1993 to 2009).

1. Annual resident population estimates by district (using 1995 boundaries) as at 30 June 1995 to 2000 were obtained from Statistics New Zealand (R. Speirs, personal communication).

2. The estimates for Auckland city, Manukau city, Waitakere City, North Shore City, Rodney, Franklin, and Papakura were amalgamated into a single Auckland district. Similarly, the Christchurch City and Banks Peninsula estimates were combined to reflect the amalgamation of these two districts in 2006.

3. Annual resident population estimates by district (using 2013 boundaries) for 2001 to 2009 were obtained from the Statistics New Zealand Infoshare database.

4. The population estimates by district (with 2013 boundaries) were adjusted to apply to the 1995 boundaries. The 1995 boundaries were used (bar the district amalgamations noted above) as these boundaries were likely to be the most 
representative of those used when districts of domicile were actually recorded in the national minimum dataset for hospital events. The adjustment was accomplished by calculating the ratio of the 1995-boundary estimate to the 2013-boundary estimate for each district in 2000 (the latest year for which estimates were available for both sets of boundaries). The 2001-2010 population estimates were multiplied by this ratio to adjust for the very minor boundary differences occurring.

5. Finally, linear interpolation was used to convert the annual population estimates to daily estimates.

National population estimates were also required for the brief analysis of trends in self-harm and temperature reported at the end of the results section. National resident population estimates were obtained from the Statistics New Zealand Infoshare database for 1993 to 2009 (mean of year ending 31 December).

The size of the populations of the districts studied varied widely. For example, the mean population over the study period ranged from over 1.2 million in Auckland to just 707 in the Chatham Islands. Five districts had a mean population of over 100,000 (averaged over the study period), these districts being Hamilton City, Wellington City, Christchurch City, Dunedin City, and Auckland. Over the study period, the population of New Zealand increased from approximately 3.6 million in 1993 to 4.3 million in 2009.

\section{Additional Information about Results}

The following additional information about the results focuses primarily on issues relating to the distributional assumptions of the methods employed. In addition, the final subsection provides a re-analysis of the study data using Bayesian rather than frequentist methods.

\section{Effects of geographical variation in temperature}

As mentioned in the article text, overdispersion was checked for all the models reported in the results section by calculating the ratio of the Pearson chi-square statistic to its degrees of freedom for each fitted model. This ratio should be close to one in the absence of overdispersion. In the case of the geographical comparison analysis, the use of a negative binomial model (as reported in the article text) was used in order to avoid overdispersion that 
was present when a simpler Poisson model was used. A Poisson model for counts of selfharm across districts implied a negative effect of temperature, $B=-0.081,95 \%$ CI [-0.087, 0.074 ], but the chi-square to degrees of freedom ratio was 52.9:1, indicating very substantial overdispersion (this ratio should be close to one). A negative binomial model was used instead, and reported in the article text.

The chi-square to degrees of freedom ratio of 1.09 for this model suggested that the negative binomial was reasonably successful in combating overdispersion. However, a negative binomial model is not the only model that can be used in the presence of overdispersion. Another possibility is the quasi-Poisson model. Whereas the negative binomial model specifies the predicted variance as a quadratic function of the predicted mean of the response variable (for a given level of the predictor variables), the quasi-Poisson model specifies the conditional variance as a multiplicative function of the predicted mean. The quasi-Poisson model tends to give greater weight to observations with large counts of the response variable (Ver Hoef \& Boveng, 2007). This means that a quasi-Poisson model would give greater weight to districts with larger populations and therefore more incidents of selfharm.

Because both the negative binomial model and the quasi-Poisson model are plausible choices for the analysis of geographical variation, we include coefficients from the estimated models with a quasi-Poisson distribution (see ESM Table 2). The results shown can be compared with the coefficients when using the negative binomial distribution in Table 2 of the main text. In the uncontrolled model for geographical variation reported in the main text and using a negative binomial model, the estimated effect of temperature was negative, $B=$ 0.004, but with a confidence interval spanning zero. With a quasi-Poisson distribution, the estimated effect of temperature in the uncontrolled model is much more strongly negative, $B$ $=-0.081,95 \%$ CI [-0.128, -0.032$]$. However, in the controlled model, the point estimate of the effect of temperature is positive but with a confidence interval spanning zero in both the negative binomial and quasi-Poisson analyses, indicating greater consistency in substantive results across the two methods used. 
ESM Table 2

Coefficients for quasi-Poisson Geographical Variation Models

\begin{tabular}{|c|c|c|c|c|c|c|}
\hline \multirow[b]{2}{*}{ Coefficient } & \multicolumn{3}{|c|}{$\begin{array}{r}\text { Uncontrolled model } \\
95 \% \mathrm{CI}\end{array}$} & \multicolumn{3}{|c|}{ Controlled model } \\
\hline & Est. & lower & upper & Est. & lower & upper \\
\hline Intercept & 6.652 & 6.577 & 6.726 & 6.599 & 6.516 & 6.679 \\
\hline Log population $^{*}$ & 0.953 & 0.902 & 1.005 & 1.023 & 0.926 & 1.120 \\
\hline Temperature $\left({ }^{\circ} \mathrm{C}\right)$ & -0.081 & -0.128 & -0.032 & 0.025 & -0.052 & 0.102 \\
\hline Radiation (MJ/m²) & & & & 0.010 & -0.083 & 0.103 \\
\hline Percentage European & & & & -0.018 & -0.045 & 0.011 \\
\hline Percentage Māori & & & & -0.008 & -0.029 & 0.014 \\
\hline Percentage Asian & & & & -0.091 & -0.154 & -0.027 \\
\hline Percentage aged 15-39 & & & & 0.095 & 0.043 & 0.147 \\
\hline Percentage aged 40-64 & & & & 0.011 & -0.059 & 0.081 \\
\hline Percentage aged 65+ & & & & 0.103 & 0.054 & 0.152 \\
\hline
\end{tabular}

Notes. *Each variable was centered around its cross-district mean, except for population which was centered around the logarithm of the cross-district mean population estimate. Generalized linear model with quasiPoisson distribution and log link used. $N=67$ districts. Quasi-Poisson dispersion parameter $=52.9$ for uncontrolled model, and 30.4 for controlled model.

\section{Effect of seasonal variation in temperature}

\section{Centering procedure.}

As noted in the text, the method for capturing seasonal variation in temperature in a statistical model was to calculate a mean temperature for each of the 365 days of the calendar year for each district. This calculation does in fact include both geographical and seasonal variation in the resulting temperature estimates for each calendar day and district. However, the use of random intercepts across districts in the linear mixed model means that in effect the influence of geographical variation in temperature-and all other geographical factors influencing self-harm rate-were controlled. Thus, the resulting estimate for the effect of temperature refers solely to seasonal variation in temperature. Effectively identical results were found if the seasonal norm temperatures were group-mean centered around the mean temperature within each district.

\section{Partial dates}

There was an apparent excess of self-harm incidents on the first day of each year (mean 11.5 incidents per day), and, to a slight extent, the first days of the remaining months 
(mean 8.1 incidents per day). In comparison, there were 7.6 incidents per day in the remainder of the calendar year. This was likely due to the fact the National Minimum Dataset allows partial dates to be entered for dates of injury. When an injury date is entered with a month and year but no day, it is recorded in the database as having occurred on the first day of the month. When a date is entered with no month or day, but with a year, it is recorded as having occurred on the first day of the year. This was a potential problem given the substantial excess of self-harm incidents that appeared to have happened on New Year's Day, a particularly warm day of the calendar year in New Zealand. However, adding a control for first day of year, and first day of month, to the models reported in the seasonal variation subsection, resulted in no substantial change to the results shown. (i.e., coefficients changed by less than 0.001).

\section{Effects of irregular variation in temperature}

One potential point of concern with relation to distributional assumptions in the analysis of the effects of irregular daily variation in temperature was that the mean number of self-harm incidents per date and district was quite low $(M=0.11)$, with the majority $(91 \%)$ of dates within each district having no self-harm incidents resulting in hospitalisation. The Poisson model is well suited to counts of rare events, however, and the $\chi^{2} / d f$ ratio of 0.97 (in both the model without radiation controlled as well as the model with radiation controlled) indicated no evidence of violation of the assumptions of the Poisson model. Inspection of a plot of nationally averaged daily temperature anomalies vs. daily self-harm rate, with a line of best fit estimated using a loess smoother, also showed no evidence of non-linearity in the relationship between temperature anomalies and self-harm rate.

\section{Alternative Bayesian analysis}

The analyses in the main text are reported without any use of statistical significance testing, given the many known problems with such tests (Cohen, 1994; Gigerenzer, Krauss, Vitouch, \& Kaplan, 2004; Gill, 1999; Wagenmakers, 2007). Instead, confidence intervals were used as the primary inferential tool. Nevertheless, the analyses used were frequentist in nature. In the frequentist interpretation of probability, probability refers to the limit of the relative frequency of some event over a large number of trials. Frequentist confidence intervals have a rather unintuitive interpretation: If we were to repeat a study a very large number of times, with a new dataset each time, and calculate a 95\% confidence interval for a 
parameter in each case, then 95\% of these intervals should include the true population parameter. We technically cannot say, however, that that there is a 95\% probability that a specific calculated 95\% confidence interval actually contains the true population parameter. The true parameter is a fixed quantity, unchanging over multiple trials, and thus the frequentist interpretation of probability does not allow us to make probability statements about whether or not it falls in a specific interval. Similarly, a frequentist interpretation of probability does not permit statements about the probability that some hypothesis is true or false.

Another interpretation of probability is the Bayesian interpretation, where probability refers to a degree of belief in some proposition. This broader interpretation of probability allows for the making of probability statements about whether a particular hypothesis is true, or about whether a parameter falls within some interval. The Bayesian interpretation of probability is linked to Bayes' theorem, which shows how prior (existing) knowledge or beliefs can be combined with new observed data to produce a posterior probability distribution. This posterior probability distribution may simply be a figure indicating the probability that a proposition is true, or it may be a continuous probability distribution. One might obtain, for example, a continuous posterior distribution for the effect of temperature on self-harm incidence, with this distribution indicating which values of the effect of temperature are more and less probable (taking into account both prior knowledge and the data observed). A general introduction to Bayesian data analysis can be found in Kruschke (2010).

As an alternative to the analyses reported in the main text, Bayesian analyses were also performed. The main outputs reported from these analyses are credible intervals. Credible intervals are the Bayesian analog of frequentist confidence intervals, but unlike confidence intervals they have a very intuitive interpretation: There is a 95\% probability that the true parameter falls within the 95\% credible interval (given the priors specified and data observed). This is one major advantage of Bayesian data analysis, although in some cases (e.g., when an uninformative ${ }^{2}$ prior distribution is used), frequentist confidence intervals will approximate Bayesian credible intervals (see Greenland \& Poole, 2013).

${ }^{2}$ An uninformative prior distribution for a parameter is one that gives no or very limited information about which values of the parameter are more probable than others. It indicates a state of ignorance about the value of the parameter (prior to seeing the data at hand). For example, a (very) uninformative prior for a regression coefficient would be a uniform distribution on $[-\infty, \infty]$, indicating that the parameter can fall anywhere on the real number line, with all values being equally probable. 
In the main text, frequentist models estimating the effects of geographical, seasonal, and irregular variation in temperature were reported. For each of the three components of variation, two models were reported: One with just population controlled, and one with additional control variables (including radiation). Bayesian versions of each of these models were also estimated, with their key outputs reported here, and exactly the same control variables and random effects specified in each case as in the main article. Bayesian generalized linear models were fit for the geographical analysis using the bayesglm function in the R package arm version 1.7-03 (Gelman et al., 2014). The quasi-Poisson distribution was used in the geographical analysis instead of the negative binomial, given that the negative binomial distribution is not as readily implemented in $\mathrm{R}$ without using additional software. Bayesian generalized linear mixed models were estimated using the package MCMCglmm version 2.21 (Hadfield, 2010).

One of the main challenges in a Bayesian analysis is the specification of appropriate prior distributions. The prior probability distributions specified for the models reported incorporated informative priors only for the effect of temperature (the output of most interest), and the effect of population (a particularly important control variable for which strong prior information was available). For the effect of temperature (regardless of whether geographical, seasonal, or irregular), a normal distribution was specified with mean zero and standard deviation of 0.01 , indicating that an increase in self-harm incidence of between -1 and $+1 \%$ for every $1{ }^{\circ} \mathrm{C}$ was most plausible, and an effects of more than $3 \%$ in either direction was very implausible. In other words, the effect of temperature was expected to be reasonably small, given the findings previously reported in this area, and the relatively small effects of temperature on suicide found in a similar study in New Zealand (Williams, Hill, \& Spicer, in press). The prior for the effect of $\log$ population was a normal distribution with $M=1$, and $S D=0.03$, given that it seemed reasonable to expect the incidence of self-harm to be approximately proportional to population size. Uninformative priors $(M=0$, variance $=$ $1.0 \times 10^{10}$ ) were specified for the other fixed effects (the intercepts, and the demographic controls in the geographical analysis). In other words, essentially no pre-existing knowledge or beliefs about the likely values of these parameters were incorporated into the analysis. The default uninformative prior in the MCMCglmm package was also used for random effects, being an (improper) inverse Wishart with parameters nu $=0$ and $\mathrm{V}=1$.

Coefficients from the Bayesian models are reported in ESM Table 3. For brevity, we report only the point estimates and credible intervals for the effect of temperature from each model, and provide the frequentist confidence interval from the corresponding original 
analysis in the main text for comparison. For the most part, the results of the Bayesian and frequentist analyses are very similar: The point and interval estimates for the effect of seasonal and irregular daily variation in temperature are nearly identical, for example. In the geographical analysis, the point estimate and credible interval limits for the effect of temperature are shrunk toward zero in comparison to the frequentist analysis. This reflects the fact that the smaller sample size ( $N=67$ districts) in the geographical analysis meant that the prior distribution - and its assumption that small effects of temperature were most plausible-exerted a stronger effect on the results than was the case for the seasonal and irregular analyses. 
ESM Table 3

Comparing Bayesian and Frequentist Models: Coefficients For Temperature

Frequentist model
95\% confidence
interval

Bayesian model

95\% credible

interval

Model Est. Lower Upper Est. Lower Upper

\section{Geographical variation}

\section{in temperature}

Temp effect in

$\begin{array}{lllllll}\text { uncontrolled model } & -0.004 & -0.062 & 0.054 & -0.002 & -0.008 & 0.005\end{array}$

Temp effect in controlled

model

$\begin{array}{llllll}0.050 & -0.035 & 0.135 & 2.5 \times 10-4 & -0.006 & 0.007\end{array}$

\section{Seasonal variation in}

\section{temperature}

Temp effect in model

without radiation

$\begin{array}{llllll}0.005 & 0.002 & 0.008 & 0.005 & 0.002 & 0.007\end{array}$

Temp effect in model with

radiation

$\begin{array}{llllll}0.001 & -0.004 & 0.005 & 0.001 & -0.003 & 0.006\end{array}$

\section{Irregular daily variation}

Temp effect in model

without radiation

0.007

0.003

0.011

0.006

0.002

0.010

Temp effect in model with

radiation

0.007

0.003

0.012

0.007

0.001

0.011

Notes. Bayesian generalized linear model (quasi-Poisson, log link) used for geographical variation models. Bayesian generalized linear mixed model (Poisson, log link) used for remaining models. The specification of control variables and random effects was the same as in the corresponding frequentist models reported in the main text. 


\section{References for Electronic Supplementary Materials}

Cohen, J. (1994). The earth is round (p<. 05). American Psychologist, 49(12), 997-1003. http://doi.org/10.1037/0003-066X.49.12.997

Gelman, A., Su, Y.-S., Yajima, M., Hill, J., Pittau, M. G., Kerman, J., ... Dorie, V. (2014). arm: Data analysis using regression and multilevel/ hierarchical models. Retrieved from http://cran.r-project.org/web/packages/arm/

Gigerenzer, G., Krauss, S., Vitouch, O., \& Kaplan, D. (2004). The null ritual: What you always wanted to know about significance testing but were afraid to ask (pp. 391408). Retrieved from http://www.sozialpsychologie.uni-frankfurt.de/wpcontent/uploads/2010/09/GG_Null_20042.pdf

Gill, J. (1999). The insignificance of null hypothesis significance testing. Political Research Quarterly, 52(3), 647 -674. http://doi.org/10.1177/106591299905200309

Greenland, S., \& Poole, C. (2013). Living with p values: resurrecting a Bayesian perspective on frequentist statistics. Epidemiology, 24(1), 62-68. http://doi.org/10.1097/EDE.0b013e3182785741

Hadfield, J. D. (2010). MCMC methods for multi-response generalized linear mixed models: The MCMCglmm R package. Journal of Statistical Software, 33(2), 1-22.

Kruschke, J. K. (2010). Doing Bayesian data analysis: a tutorial with R and BUGS (1st ed.). Academic Press.

NIWA. (n.d.). CliFlo national climate database. Retrieved 3 October 2013, from http://cliflo.niwa.co.nz/

Statistics New Zealand. (2012). Estimated resident population for territorial authority areas, at 30 June (1996+) (annual-Jun). Retrieved 6 November 2012, from http://www.stats.govt.nz/infoshare/ 
Ver Hoef, J. M., \& Boveng, P. L. (2007). Quasi-poisson vs. negative binomial regression: How should we model overdispersed count data? Ecology, 88(11), 2766-2772.

Wagenmakers, E. J. (2007). A practical solution to the pervasive problems of p values. Psychonomic Bulletin \& Review, 14(5), 779-804. http://doi.org/10.3758/BF03194105 Williams, M. N., Hill, S. R., \& Spicer, J. (in press). Will climate change increase or decrease suicide rates? The effect of temperature on suicide incidence in New Zealand. Climatic Change. 
Do hotter temperatures increase the incidence of self-harm hospitalisations?

\author{
Williams, MN
}

2016-02-17

http://hdl.handle.net/10179/16662

22/04/2023 - Downloaded from MASSEY RESEARCH ONLINE 